between specialists and primary care physicians, to assist harmonisation, and to design and deploy relevant educational tools (see www.eaaci.net).

However, the impact of allergies has only recently been recognised at the political level in Europe, mostly in relation to respiratory allergies. ${ }^{15}$ This is an important step, but it lags behind the observed epidemiological trends with increases in systemic disease entities such as food allergy. In all, there is little doubt that recognition and prioritisation of allergy education in primary care is probably the only way to improve patient outcomes and to prevent devastating consequences in public health.

Conflicts of interest The authors declare that they have no conflicts of interest in relation to this article.

Commissioned article; not externally peer-reviewed; accepted 8th February 2013; online 21st February 2013

(C) 2013 Primary Care Respiratory Society UK. All rights reserved

http://dx.doi.org/10.4104/pcrj.2013.00021

Prim Care Respir J 2013; 22(1): 5-6

\section{References}

1. Worldwide variation in prevalence of symptoms of asthma, allergic rhinoconjunctivitis, and atopic eczema: ISAAC. The International Study of Asthma and Allergies in Childhood (ISAAC) Steering Committee. Lancet 1998;351(9111): 1225-32. http://dx.doi.org/10.1016/S0140-6736(97)07302-9

2. Anandan C, Gupta R, Simpson CR, Fischbacher C, Sheikh A. Epidemiology and disease burden from allergic disease in Scotland: analyses of national databases. J R Soc Med 2009;102(10):431-42. http://dx.doi.org/10.1258/jrsm.2009.090027

3. Royal College of Physicians and Royal College of Pathologists Working Party. Allergy services: still not meeting the unmet need. 2010 http://bookshop.rcplondon.ac.uk/contents/pub317-44f79458-267d-4006-af053f0e468e22c5.pdf (accessed February 2013).
4. Levy ML, Price D, Zheng X, Simpson C, Hannaford P, Sheikh A. Inadequacies in UK primary care allergy services: national survey of current provisions and perceptions of need. Clin Exp Allergy 2004;34(4):518-19. http://dx.doi.org/10.1111/j.13652222.2004.1945.x

5. Hazeldine $M$, Worth $A$, Levy ML, Sheikh A. Follow-up survey of genera practitioners' perceptions of UK allergy services. Prim Care Respir J 2010;19(1):846. http://dx.doi.org/10.4104/pcri.2010.00002

6. Ewan PW, Durham SR. NHS allergy services in the UK: proposals to improve allergy care. Clin Med 2002;2(2):122-27.

7. Ellis J, Rafi I, Smith $\mathrm{H}$, Sheikh A. Identifying current training provision and future training needs in allergy available for UK general practice trainees: national crosssectional survey of General Practitioner Specialist Training programme directors. Prim Care Respir J 2013;22(1):19-22 http://dx.doi.org/10.4104/pcrj.2012.00087

8. Prescott $\mathrm{S}$, Allen KJ. Food allergy: riding the second wave of the allergy epidemic Pediatr Allergy Immunol 2011;22(2):155-60. http://dx.doi.org/10.1111/j.13993038.2011.01145.x

9. Anderson HR, Gupta R, Strachan DP, Limb ES. 50 years of asthma: UK trends from 1955 to 2004. Thorax 2007;62(1):85-90. http://dx.doi.org/10.1136/ thx.2006.066407

10. Gupta R, Sheikh A, Strachan DP, Anderson HR. Time trends in allergic disorders in the UK. Thorax 2007;62(1):91-6. http://dx.doi.org/10.1136/thx.2004.038844

11. Fox M, Mugford M, Voordouw J, et al. Health sector costs of self-reported food allergy in Europe: a patient-based cost of illness study. Eur J Public Health 2013 (in press). http://dx.doi.org/10.1093/eurpub/ckt010

12. Gupta RS, Springston EE, Kim JS, et al. Food allergy knowledge, attitudes, and beliefs of primary care physicians. Pediatrics 2010;125(1):126-32. http://dx.doi.org/ 10.1542/peds.2009-1116

13. Haahtela T, von Hertzen L, Makela M, Hannuksela M. Finnish Allergy Programme 2008-2018--time to act and change the course. Allergy 2008;63(6):634-45

14. de Monchy JG, Demoly P, Akdis CA, et al. Allergology in Europe, the blueprint. Allergy 2013 (in press).

15. Samolinski B, Fronczak A, Wlodarczyk A, Bousquet J. Council of the European Union conclusions on chronic respiratory diseases in children. Lancet 2012; 379(9822):e45-46. http://dx.doi.org/10.1016/S0140-6736(12)60514-5

\title{
Is education at the crossroads?
}

\section{See linked articles by Ulrik et al. on pg 23 and Patel et al.}

on pg 29

\section{*Ron Tomlins ${ }^{1}$}

1 Adjunct Associate Professor, Discipline of General Practice, Western Clinical School, University of Sydney, Sydney, Australia; Chair, COPD Expert Reference Group, Improvement Foundation of Australia; Treasurer, IPCRG

*Correspondence: Professor Ron Tomlins, PO Box 436,

Cherrybrook, NSW 2126, Australia

Tel: +61412042007 Fax: +61294840073

E-mail: ron_tomlins@optusnet.com.au

Continuing education is a challenge for primary care physicians. ${ }^{1-3}$ The changing emphasis on long-term conditions, the escalating cost of health care delivery, and the impact of new knowledge, new technologies and new treatments, all clash with daily pressures to deliver the highest possible quality of care to our patients. In this issue of the $P C R J$, two papers explore models of delivery of education to primary care physicians in general practice in Australia and Denmark. ${ }^{4,5}$

The Australian study ${ }^{4}$ reports on a study to translate the methodology of Physician Asthma Care Education (PACE), developed by Professor Noreen Clark in Michigan, USA, with adaptations to Australia. PACE teaches clinicians about current best clinical practice in asthma, communicating more effectively with patients, and how to support patients' management efforts. An interactive seminar lasting for five hours over two sessions with trusted knowledge experts, video resources, case studies and advice on access to remuneration formed the educational intervention. The study was funded by the Australian Government, at a cost of AU\$2,000 per practitioner trained.

The Danish study ${ }^{5}$ focused on COPD education delivered in the general practitioner's own practice. The principal intervention was a 3hour teaching session with a respiratory specialist, supported by up to five additional visits from a representative of the sponsoring pharmaceutical company focusing on coding of patients, spirometry and device technique. There are some questions about the identification of patients with COPD based solely on prescribing records, but as the purpose of the study was to demonstrate a change 
in practice as a result of the educational intervention, the authors argue that the matched control group methodology minimised possible confounders. The cost of training was not recorded.

Both studies ${ }^{4,5}$ demonstrated positive outcomes. The Danish study showed a trend that the educational intervention had a positive impact on adherence to guidelines, but the findings were only significant for increased spirometry testing in a subgroup of practices identified as having a high potential for improvement. The PACE study showed that the US programme could be translated to Australia and successfully implemented, but longer term health outcomes shown for patients in the US programme could not be evaluated in the time available. However, we should critically examine the continuing education of primary care physicians in a broader, global context.

The translation of a physician's knowledge to the attainment of better health outcomes by his or her patients is, on the one hand our raison d'être, and on the other, a small element in a complex series of interactions that are necessary to achieve those results. Informed patients increasingly expect to be at the centre of care, and expect to be involved in decision-making in relation to their health. ${ }^{6}$ Advances in mobile communications technology will result in most people in the world having access to high quality information, and this will open up exciting and challenging opportunities ${ }^{7}$ for the delivery of health care advice remotely. Traditional cultural influences that underpin current health and illness behavior will diminish, with the sharing of common global aspirations. Simultaneously, the emergence of teams to deliver care to people with long-term conditions ${ }^{8}$ will enhance the role of the primary care clinician, from 'care provider' to 'care coordinator'.

Similarly, the applicability to primary care of clinical practice guidelines developed in settings remote from primary care is being questioned - as highlighted by D'Urzo in his editorial in this issue, and by Gruffydd-Jones recently. ${ }^{9}$ Even in specialist groups, clinical practice recommendations by bodies such as the UK National Institute for Health and Clinical Excellence (NICE) are not universally adopted..$^{10}$

Education per se leading to changes in clinical practice has been shown to be most effective when delivered as a parcel of multifaceted interventions, ${ }^{1-3}$ but there is little understanding of how readily models that are successful in a single region or culture can be adapted to other regions, cultures, health funding systems or provider groups." Inevitably, the cost of delivery will limit the way in which education can be delivered. While many countries will eschew pharmaceutical company assistance, other countries may not be able to afford programmes that are not subsidised ${ }^{12}$ - another manifestation of Tudor Hart's Inverse Care Law? ${ }^{13}$ The efficiency of targeted education noted in the Danish study is worthy of further consideration - aiming to provide preferential access to those practitioners who most need the education.

The nature of the daily work of the primary care practitioner is shifting from the acute management of diseases in a single episode of care, to prevention and the extended management of people (and communities) with a diverse range of long-term conditions. ${ }^{14}$ Accordingly, models of education may need to address the common generic elements of chronic disease management ${ }^{15}$ - assessment, treatment, monitoring and communication - with modules relating to best clinical practice for a specific disease.
Are our methods of educating health professionals sufficiently robust to cope with these pressures? And are our institutions academic and professional - sufficiently flexible to support quality education leading to affordable quality outcomes in the face of the pressures of global social marketing?

There is, therefore, a role for communities of practice like the International Primary Care Respiratory Group (IPCRG) and its member bodies to explore innovative ways to achieve our goal of improving the respiratory health of people worldwide. The IPCRG E-Quality programme, ${ }^{3}$ launched in 2012, seeks to support small scale educational initiatives, and to demonstrate changes in clinician behaviour and improvement of health outcomes. Strategic alliances with other groups such as Wonca, foundations seeking to effect improvement of care or to implement proven strategies to improve health of populations, consumer organisations, and specialist groups, will add to the momentum for change. In this way, we hope to be able to meet the challenges involved in the continuing education of primary care physicians.

Conflicts of interest The author assisted in the recruitment of general practitioners and patients for the Australian component of the PACE study but had no further involvement in the study. He was a member of the IPCRG Education Subcommittee that funded and oversaw the development of the IPCRG E-Quality program.

Commissioned article; not externally peer-reviewed; accepted 8th February 2013; online 21st February 2013

(c) 2013 Primary Care Respiratory Society UK. All rights reserved http://dx.doi.org/10.4104/pcrj.2013.00020 Prim Care Respir J 2013; 22(1): 6-8

\section{References}

1. Booth BJ, Snowden T, Harris MP, Tomlins R. Safety and quality in primary care: the view from general practice. Australian J Primary Health 2008;14(2):1927.http://dx.doi.org/10.1071/PY08018

2. Comino EJ, Powell Davies $G$, Krastev $Y$, et al. A systematic review of interventions to enhance access to best practice primary health care for chronic disease management, prevention and episodic care. BMC Health Sciences Research 2012;12:415-23. http://dx.doi.org/10.1186/1472-6963-12-415

3. McDonnell J, Williams $\mathrm{S}$, Chavannes $\mathrm{NH}$, et al. Effecting change in primary care management of respiratory conditions: a global scoping exercise and literature review of educational interventions to inform the IPCRG's E-Quality initiative. Prim Care Respir J 2012;21(4):421-36. http://dx.doi.org/10.4104/pcrj.2012.00071

4. Patel MR, Shah S, Cabana MD, et al. Translation of an evidence-based asthma intervention: Physician Asthma Care Education (PACE) in the United States and Australia. Prim Care Respir J 2013;22(1):29-36. http://dx.doi.org/10.4104/ pcrj.2012.00093

5. Ulrik CS, Sorensen TB, Hejmark TB, Olsen KR, Vedsted P. Adherence to COPD guidelines in general practice: impact of an educational programme delivered on location in Danish general practices. Prim Care Respir J 2013;22(1):23-28. http://dx.doi.org/10.4104/pcrj.2012.00089

6. Boyer CA, Lutfy KE. Examining critical health policy issues within and beyond the clinical encounter: patient-provider relationships and help-seeking behavior. $J$ Health Soc Behav 2010;51 Suppl:S80-93. http://dx.doi.org/10.1177/ 0022146510383489

7. Yellowlees $P$, Odor $A$, Patrice $K$, et al. Disruptive innovation: the future of healthcare? Telemed J E Health 2011;17(3):231-4. http://dx.doi.org/10.1089/ tmj.2010.0130

8. Mohr DC, Benzer JK, Young GJ. Provider workload and quality of care in primary care settings: moderating role of relational climate. Med Care 2013;51(1):108-14. http://dx.doi.org/10.1097/MLR.0b013e318277f1cb 
9. Gruffyd-Jones K. GOLD guidelines 2011: what are the implications for primary care? Prim Care Respir J 2012;21(4):437-41. http://dx.doi.org/10.4104/ pcrj.2012.00058

10. Basu M, Duckett JR, Moran P, Freeman R. Clinician's views on the NICE guideline on the management of female urinary incontinence. J Obstet Gynaecology 2009;29(6):529-32. http://dx.doi.org/10.1080/01443610903003167

11. Beach MC, Gary TL, Price EG, et al. Improving health care quality for racial/ethnic minorities: a systematic review of the best evidence regarding provider and organization interventions. BMC Public Health 2006;6:104-14. http://dx.doi.org/10.1186/1471-2458-6-104

12. Grindon GE, Lavis JN, Becerra-Posada F, et al. Bridging the gaps between research, policy and practice in low- and middle-income countries. CMAJ 2010;182(9):E362372. http://dx.doi.org/10.1503/cmaj.081165

13. Hart JT. The inverse care law. Lancet 1971;1:405-12. http://dx.doi.org/ 10.1016/S0140-6736(71)92410-X

14. Schoen C, Osborn R, Squires D, Doty M, Pierson R, Applebaum S. New 2011 survey of patients with complex care needs in eleven countries find that care is often poorly coordinated. Health Aff (Millwood) 2011;30(12):2437-48. http://dx.doi.org/10.1377/hlthaff.2011.0923

15. Speight J. Managing diabetes and preventing complications: what makes the difference? Med J Aust 2013;198(1):1-2. http://dx.doi.org/10.5694/mja12.11489

\section{Usefulness of the COPD assessment test (CAT) in primary care}

\section{See linked article by Gruffydd-Jones et al. on pg 37}

\section{*Arnulf Langhammer', Rupert Jones ${ }^{2}$}

1 Professor, HUNT Research Centre, Department of Public Health and General Practice, Norwegian University of Science and Technology, Levanger, Norway

2 Clinical Research Fellow, Plymouth University Peninsula School of Medicine and Dentistry, Plymouth, UK

*Correspondence: Professor Arnulf Langhammer, HUNT Research Centre, Department of Public Health and General Practice, Norwegian University of Science and Technology, Forskningsveien 2, 7600 Levanger, Norway

Tel: +47 74075187 Fax: +47 74141255

E-mail: arnulf.langhammer@ntnu.no

Optimum management of COPD can improve prognosis and reduce the impact of the disease on quality of life and health status. For this purpose, optimal assessments of multiple dimensions of the disease are necessary.

Previous guideline recommendations were often based on limited evidence of therapeutic effectiveness and limited study of the feasibility of incorporating recommendations into primary care. Assessment of COPD severity was based solely on the degree of bronchial obstruction, despite a weak correlation between lung function parameters and perceived symptoms and limitations. ${ }^{1}$ However, current guidelines recommend assessment of patientfocused outcomes; these can be measured using various validated health status measures, from the simple one-question Medical Research Council (MRC) dyspnoea grade to the more complex St George's Respiratory Questionnaire (SGRQ).

The difficult question is how we should incorporate patientrelated outcome measures into routine primary care practice. One solution has been to use composite measures of disease severity including lung function and health status. The BODE index (Body mass index, Obstruction, Dyspnea, Exercise) uses the MRC as a measure of health status and has proved to be robust as a measure of disease severity and prognosis, ${ }^{2}$ but is not widely used in routine care. The latest GOLD guidelines ${ }^{3}$ suggest dividing patients into four categories based on current symptoms (assessed using the MRC or the COPD assessment test (CAT)), percent predicted $\mathrm{FEV}_{1}$, and the number of exacerbations. However, this system has met with significant objections since it was neither derived nor validated statistically, is complex to use, and may not be suitable for primary care. ${ }^{4}$

Valid and reliable tools for health status measurement in COPD patients are beneficial for comparative studies between populations as well as for measuring short- and long-term changes, perhaps especially for health authorities, researchers and pharmaceutical companies. Pivotal questions remain, however, such as whether these tools improve the communication between health professional and patient, contribute to improved patient outcomes, or if they are feasible to use in routine general practice. Newer scales could facilitate use in routine care.

One of the aims during the development of the CAT was to improve communication between COPD patients and the clinician, thus enabling a common understanding of the severity and impact of the disease. ${ }^{3}$ This is not easy to determine, but in this issue of the PCRJ, Gruffydd-Jones et al. report a very interesting randomised controlled study on the utility of the CAT in primary care consultations. ${ }^{5}$ As many as 165 primary care physicians from six European countries conducted six consultations with standardised COPD patients (played by trained actors) covering a variety of COPD severities and co-morbidities. Physicians were randomised to see the patients in videoed consultations with or without the completed CAT. The physicians were scored according to their ability to identify and address A) relevant patient issues, and B) ten standard COPD issues, as well as being scored on their understanding of the case and their overall performance in 10-minute consultations. The physicians with access to the completed CAT more often achieved "high quality reviews" of the items included in COPD sub-score B, but no difference was found between the two groups as regards questions on tobacco smoking and exacerbations, non-COPD symptoms (sub-score A), co-morbidities or other consultation quality measures. Therefore, the CAT aided primary care physician assessment of COPD-related issues but not the detection of non-COPD symptoms or co-morbidities. There are, of course, limitations in standardised studies such as this, but the authors deserve credit for performing an ingeniously-designed and important study.

The Clinical COPD questionnaire (CCQ) was developed in 2003 and contains 10 items with three domains (symptoms, functional and 